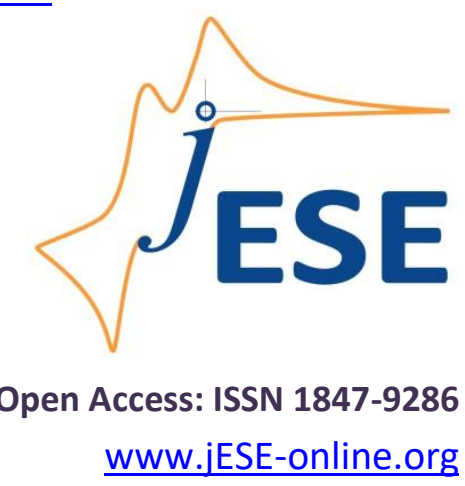

Original scientific paper

\title{
Cyclic voltammetry: A simple method for determining contents of total and free iron ions in sodium ferric gluconate complex
}

\author{
Hong Liu ${ }^{凶}$, Qiao Yu ${ }^{1}$, Yixuan Ma², Baoyu Liu ${ }^{1}$ and Hongchun Pan ${ }^{1}$ \\ ${ }^{1}$ College of Pharmaceutical Sciences, Southwest University, Chongqing, China \\ ${ }^{2}$ Affiliated Hospital of Qinghai University
}

Corresponding author: ${ }^{\circledR}$ Ihphch@126.com; Tel.:13368261386;

Received: November 1, 2019; Revised: April 3, 2020; Accepted: April 4, 2020

\begin{abstract}
Sodium ferric gluconate complex (SFGC) is the third generation of iron supplement of polysaccharide iron (III) complex (PIC). For evaluation of technological level and application value of the prepared SFGC, it would be of great significance to determine the iron content in SFGC in a simple but effective way. This paper introduces the cyclic voltammetry (CV) method for determination of iron content in SFGC. Under established optimal experimental conditions, the content of free iron ions can be directly scanned and calculated, while the total iron content can also be determined by completely acidifying SFGC into Fe ${ }^{3+}$ ions. After optimizing and screening, the optimal scanning conditions are determined as $\mathrm{pH} 3$ and $0.05 \mathrm{~V} / \mathrm{s}$ of the scanning rate. Prior CV measurements, $0.4 \mathrm{~V}$ of the enrichment potential, and 3 min of the enrichment time are found optimal. It has also been verified that $\mathrm{CO}_{3}{ }^{2-}$ ions present in the solution show little interference in the system within the experimental range of investigation. The contents of free $\mathrm{Fe}^{3+}, \mathrm{Fe}^{2+}$ ions and the total iron determined after acidhydrolysis of SFGC can be accurately calculated according to the corresponding linear relationships between peak currents and iron concentrations. In this paper, the repeatability and accuracy of the method are verified, and its feasibility as a convenient and effective method to determine the iron supplements is confirmed.
\end{abstract}

Keywords: Iron content; free iron ions content; iron supplements

\section{Introduction}

The iron-deficiency anemia is currently the most common type of anemia, which widely exists in many countries around the world, especially in the developing countries [1,2]. By inadequate iron intake, the synthesis of hemoglobin in human's body will be affected, resulting in inadequate oxygen supply to cells and tissues [1,3]. Iron-deficiency anemia has usually been treated by iron supplements. Development of iron supplements is carried out through three stages, where the third generation, namely the macromolecular compound iron supplement, is a new type of iron complex 
formed by ferric ions and the carrier of organic macromolecular complex [4]. Compared with previous two generations, the third one has higher iron content and better solubility, because iron in the complex does not exist as ions. Hence iron supplements of this new generation cause little digestive side effects and among them, the saccharide-iron complexes are under wide research work [5]. In addition to being the iron supplement, the saccharide itself has many biological activities, and is beneficial to the body by various synergistic effects after being absorbed. Therefore, the saccharide-iron (III) complex is a promising type of nutritional iron supplement $[6,7]$.

Gluconic acid sodium salt (D-SG) (Figure 1) is used as a molecular shell to effectively adsorb the metal iron ions in the solution, forming a stable iron complex. The complex is called sodium ferric gluconate complex (SFGC), having possible structure shown in Figure 2. This iron supplement is highly stable and has no toxic side effects.

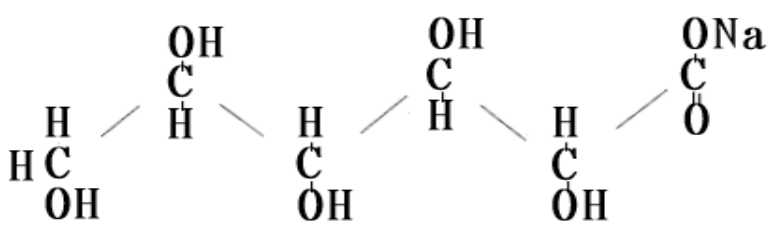

Figure 1. Molecular structure of D-SG

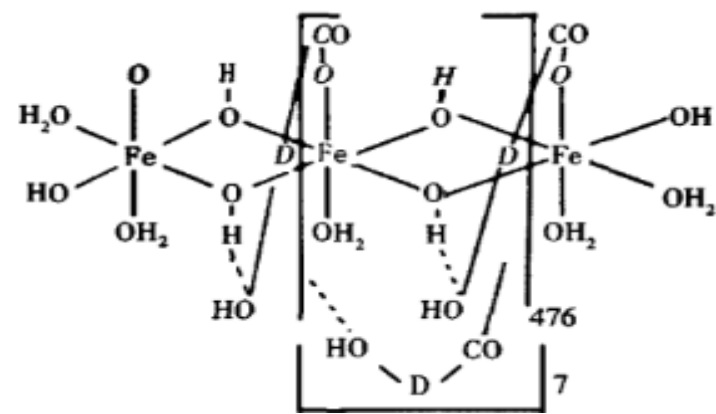

Figure 2. Proposed structure of SFGC

The iron content is one of the most important indicators to analyze the complexation process and technological results of sodium ferric gluconate complex (SFGC) preparation [8-10]. Since less content of free iron ions can reduce irritation in the digestive tract, high content of complex iron increases a status of the product. Therefore, it is important to determine the contents of free and total iron in SFGC rapidly and accurately.

So far, the determination of iron content mainly includes the methods such as potassium dichromate solution titration, phenanthroline spectrophotometry, atomic absorption spectrometry, etc. $[11,12]$. However, the titration technique not only consumes plenty of time and chemicals, but also produces a great deal of pollutants because of the utilization of toxic potassium dichromate and mercuric chloride in the operation [13]. The spectrophotometry requires a pre-treated sample with a complicated operation and has low sensitivity and poor accuracy [14]. Although the atomic absorption spectrophotometry does not require a pretreatment process, the operation is simple and fast and accuracy is high, the equipment is expensive, and difficult to popularize [15]. The most important is that all above mentioned methods cannot accurately distinguish and separately determine the contents of free iron ions and total iron in the complex when they both exist in the system. This brings difficulties to evaluation of the complexation process and outcome of the iron complex system. Therefore, it would be of great importance to develop an accurate, rapid, convenient and costefficient method for respective determinations of free iron ions and total iron in the complex.

In this paper, a classical electrochemical research method $[16,17]$, that is cyclic voltammetry technique is adopted. It allows free $\mathrm{Fe}^{3+}$ and $\mathrm{Fe}^{2+}$ ions in the sample solution to form a reversible redox system and generate current peaks by corresponding redox reactions. Based on these redox reactions, the content of free iron ions in SFGC can be determined directly, while the total iron content can be determined after conversion of SFGC into free $\mathrm{Fe}^{3+}$ ions by acid-hydrolysis. Acidhydrolysis conditions, $\mathrm{pH}$, potential scanning rate and some other experimental parameters are 
optimized in this paper, and the methodological verification is carried out in order to obtain a practical and efficient detection method.

\section{Experimental}

\section{Reagents and materials}

D-sodium gluconate (D-SG) was purchased from Chengdu Kelong Chemical Co., Ltd., Sichuan Province, China. Ultrapure water $(18.25 \mathrm{M} \Omega \mathrm{cm})$ was used throughout the experiment. All other reagents and chemicals employed in this experiment were of analytical grade.

\section{Apparatus}

The electrochemical measurements of cyclic voltammetry (CV) were performed with a CHI610E electrochemical workstation (Chenhua Co. Ltd., Shanghai, China). It contains a conventional threeelectrode system comprised of platinum as the auxiliary electrode, saturated calomel electrode as the reference electrode and 3-mm-diameter glassy carbon (GC) as the working electrode. The $\mathrm{pH}$ measurements were assayed with a FE20 FiveEasyTM pH meter (Mettler Toledo, Shanghai, China). All measurements were carried out at indoor temperature.

\section{Preparation of SFGC}

$40 \mathrm{~mL}$ of $1.18 \mathrm{~mol} / \mathrm{L} \mathrm{Na}_{2} \mathrm{CO}_{3}$ solution was added to another $40 \mathrm{~mL}$ solution which contained $10 \mathrm{~g}$ D-SG. Afterwards, the solution containing $(60 \mathrm{~mL}) 1.25 \mathrm{~mol} / \mathrm{L}$ of $\mathrm{FeCl}_{3} \cdot 6 \mathrm{H}_{2} \mathrm{O}$ was added dropwise under continuous stirring. The synthesis of the complex was performed at $\mathrm{pH} 11$ (adjusted by adding $5 \mathrm{~mol} / \mathrm{L} \mathrm{NaOH}$ ). The mixture was heated at $100{ }^{\circ} \mathrm{C}$ at least $3 \mathrm{~h}$ in the oil bath, and then filtered and cooled to room temperature. The complex was precipitated by $0.2 \mathrm{~L}$ of ethanol. After $4 \mathrm{~h}$ of standing, the ethanol was decanted, and the precipitate was centrifuged at $3000 \mathrm{r} / \mathrm{min}$ for $10 \mathrm{~min}$. The supernatant was decanted, and the precipitate was dissolved in $0.1 \mathrm{~L}$ redistilled water. Dialysis of the solution was used to remove unbound ions $\left(\mathrm{Cl}^{-}, \mathrm{Na}^{+}, \mathrm{Fe}^{3+}\right)$. Finally, the complex was washed successively from the dialyzed solution by ethanol and acetone and dried for $3 \mathrm{~h}$ in vacuum after decantation. Thus, the sodium ferric gluconate complex (SFGC) was obtained as a black powder.

\section{Preparation of Fe standard solutions and acid hydrolysis of SFGC}

$0.01 \mathrm{~mol} / \mathrm{L} \mathrm{Fe}^{3+}$ standard solution: $0.1351 \mathrm{~g}$ of $\mathrm{FeCl}_{3} \cdot 6 \mathrm{H}_{2} \mathrm{O}$ was dissolved in ultrapure water, mixed and diluted to the required concentration $(50 \mathrm{~mL})$. After that, the samples of standard solution were diluted to different concentrations $(0.009,0.008,0.007,0.006,0.005 \mathrm{~mol} / \mathrm{L}, 50 \mathrm{~mL})$.

$0.05 \mathrm{~mol} / \mathrm{L} \mathrm{Fe}{ }^{2+}$ standard solution: $0.4970 \mathrm{~g}$ of $\mathrm{FeCl}_{2} \cdot 12 \mathrm{H}_{2} \mathrm{O}$ was dissolved in ultrapure water, mixed and rapidly diluted to the required concentration $(50 \mathrm{~mL})$. After that, the samples of standard solution were diluted to different concentrations $(0.045,0.040,0.035,0.030,0.025 \mathrm{~mol} / \mathrm{L}, 50 \mathrm{~mL})$. As Fe $\mathrm{Fe}^{2+}$ ions are easily oxidized into $\mathrm{Fe}^{3+}$ ions, all prepared $\mathrm{Fe}^{2+}$ solutions should be used right after preparation.

SFGC acid-hydrolysis solution: $0.2500 \mathrm{~g}$ of SFGC was dissolved in ultrapure water, mixed and diluted to $5 \mathrm{~g} / \mathrm{L}(50 \mathrm{~mL})$. Hydrochloric acid solutions $(2 \mathrm{~mL})$ with different concentrations $(1,3,5$, $7 \mathrm{~mol} / \mathrm{L}$ ) were slowly added to $4 \mathrm{~mL}$ of $5 \mathrm{~g} / \mathrm{L} \mathrm{SFGC}$ solution in $25 \mathrm{~mL}$ beaker, respectively. After $5 \mathrm{~min}$ stirring, the solution was treated by acid-hydrolysis method for $5 \mathrm{~min}$ at room temperature (RT), water bath $\left(20^{\circ} \mathrm{C}\right)$ and refrigerator $\left(4^{\circ} \mathrm{C}\right)$, respectively.

\section{Test method}

To improve reproducibility and sensitivity of peak currents in CV measurements, the surface of the working GC electrode was polished successively with $1,0.3$, and $0.05 \mu \mathrm{m}$ alumina powders on a 
nylon polishing cloth to achieve the hydrophobic property, and then washed for five minutes in an ultrasonic bath of nitrate, ethanol and water respectively [18]. It is worth noting that the $\mathrm{K}_{3} \mathrm{Fe}(\mathrm{N})_{6^{-}}$ $\mathrm{KCl}$ standard solution should be scanned for the electrode testing purpose by cyclic voltammetry, where the potential difference of anode and cathode peaks of $60-80 \mathrm{mV}$ is the main criteria of well electrode working [19].

Test solutions were deoxygenated before measurements by purging with nitrogen for 5 min. After that, a three-electrode was placed, and then the system was rested for 2 min. Experimental settings included the scan rate of $0.05 \mathrm{~V} / \mathrm{s}$, and the number of cycles was 6 . Cyclic voltammograms were measured within the potential range of +1.0 to $-1.0 \mathrm{~V}$, where peak currents are recorded [20]. Standard calibration curves are plotted with $\mathrm{Fe}^{3+}$ or $\mathrm{Fe}^{2+}$ concentrations at the abscissa, and the oxidation peak currents at the ordinate axis, respectively.

\section{Results and discussion}

\section{Characteristic peak scanning of free iron ions and SFGC}

SFGC has chelated iron properties, and the presence of free iron ions will reduce stability of the composite product [21]. Therefore, the content of free iron ions in the solution is an important indicator for determining the complex iron [8,9]. Standard solutions of $0.01 \mathrm{~mol} / \mathrm{L} \mathrm{Fe}^{3+}$ and $\mathrm{Fe}^{2+}$ were scanned by $\mathrm{CV}$ and electrochemical characteristic peaks are found consistent with those reported in the literature [22,23] (Figure 3a,b). However, no electrochemical response indicated by absence of characteristic peaks of free iron ions is observed in the scanning of $1 \mathrm{~g} / \mathrm{L} \mathrm{SFGC} \mathrm{solution} \mathrm{(Figure} \mathrm{3c).}$ Hence, it is indicated that there are no free iron ions, or the content of free iron ions in SFGC solution is lower than the detection limit.

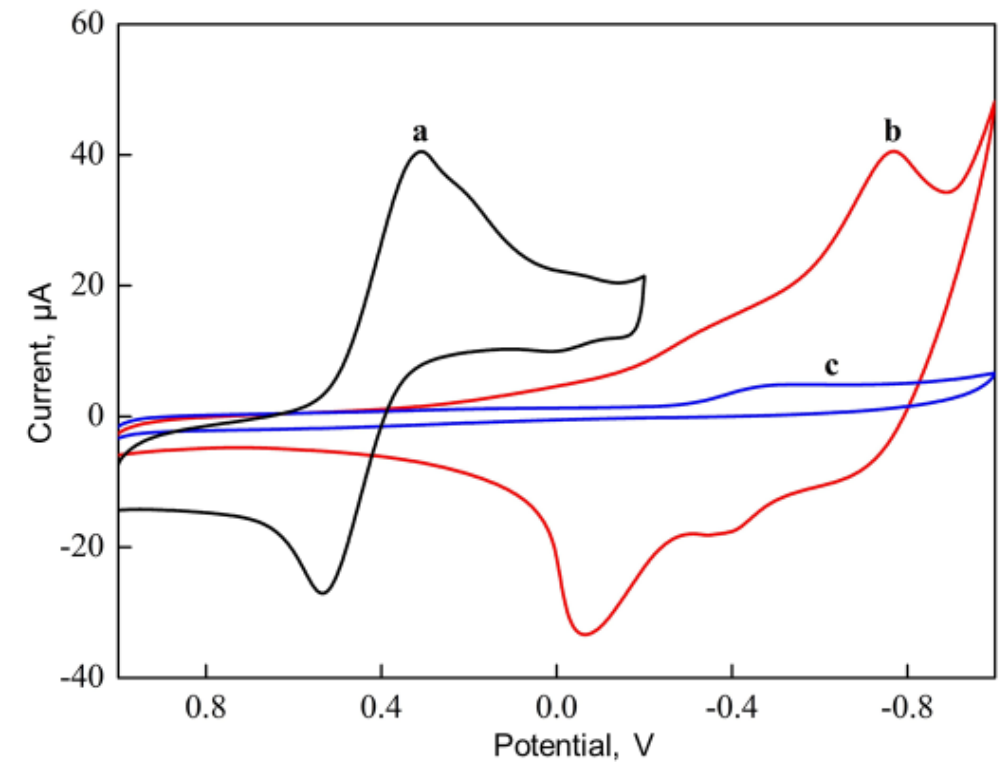

Figure 3. Characteristic peaks recorded by $\mathrm{CV}(0.05 \mathrm{~V} / \mathrm{s})$ at GC electrode in standard solutions of (a) $\mathrm{Fe}^{3+}$ ions, (b) Fe $e^{2+}$ ions, (c) SFGC.

\section{Determination of free iron ions in SFGC}

With CV technique, the corresponding electrochemical characteristic peaks can be obtained by scanning free $\mathrm{Fe}^{3+}$ and $\mathrm{Fe}^{2+}$ ions under certain conditions. In experiments, the detection conditions should be optimized in terms of $\mathrm{pH}$, potential scanning rate, as well as enrichment potential and enrichment time applied prior CV measurements. Additionally, with free $\mathrm{Fe}^{3+}$ and $\mathrm{Fe}^{2+}$ ions added to SFGC solution in the cyclic voltammetry scanning, the signal response showed a linear relationship 
with the added concentration, suggesting that the determination of free iron ions would not be affected by the chelated iron. Therefore, the content of free iron ions can be detected and calculated by this method.

\section{Optimization of detection conditions}

Determination of optimal $\mathrm{pH}$

The value of $\mathrm{pH}$ has important impact for the studied system. As the acidity will affect the hydrolysis and $\mathrm{H}^{+}$can inhibit the hydrolysis of $\mathrm{Fe}^{3+}$ [24], keeping the system stable for a certain period of time for easy measurement [19]. $\mathrm{pH}$ was adjusted to 1, 2, 3, 4, 5 and 6 respectively, for cyclic voltammetry scanning (Figure 4). At pH 1-3, the peak widths and peak currents changed little, indicating that the electrical signal within this $\mathrm{pH}$ range is relatively stable, what is beneficial for analytical determination. Since at $\mathrm{pH} 3$, the electrical signal showed the strongest response and the highest sensitivity, the optimal $\mathrm{pH}$ value was selected to 3 .

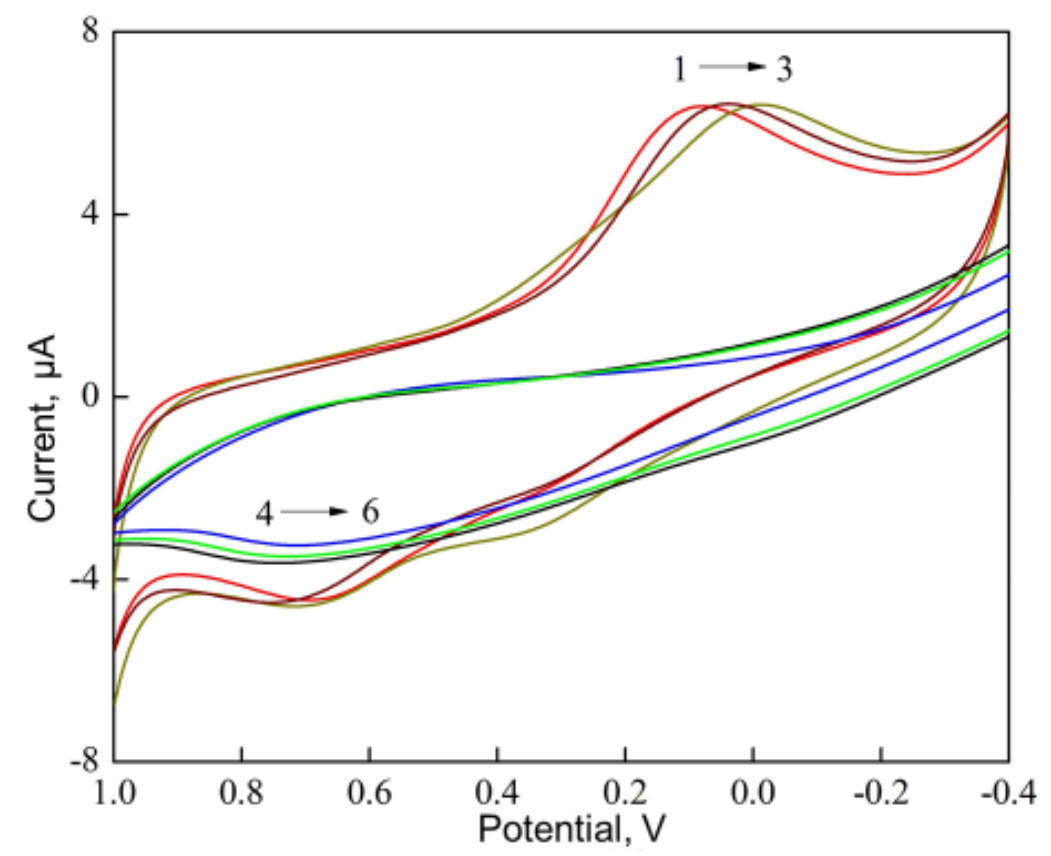

Figure 4. CV curves $(0.05 \mathrm{~V} / \mathrm{s})$ of GC electrode in diluted Fe $\mathrm{F}^{3+}$ solution at $\mathrm{pH}(1-6)$.

\section{Determination of optimal scanning rate}

Cyclic voltammetry curves were recorded for $\mathrm{Fe}^{3+}$ standard solution diluted multiple times, within the scanning potential range of +1.0 to $-0.4 \mathrm{~V}$, at scanning rates of $0.01-0.09 \mathrm{~V} / \mathrm{s}$ (Figure 5 ). It is seen in Figure 5 that as the scanning rate increases, the peak current also increases. At the same time, the oxidation peak potential is shifted positively, but the reduction peak potential is shifted negatively. When the scanning rate is too low, the electrical signal is weak and the curve peak is not so obvious, which is not conducive to the detection of $\mathrm{Fe}^{3+}$. Nevertheless, when the scanning rate is too high, the electrical signal is strong, and $\mathrm{Fe}^{3+}$ characteristic peak becomes deformed. Therefore, the optimal scan rate is chosen to be $0.05 \mathrm{~V} / \mathrm{s}$. 


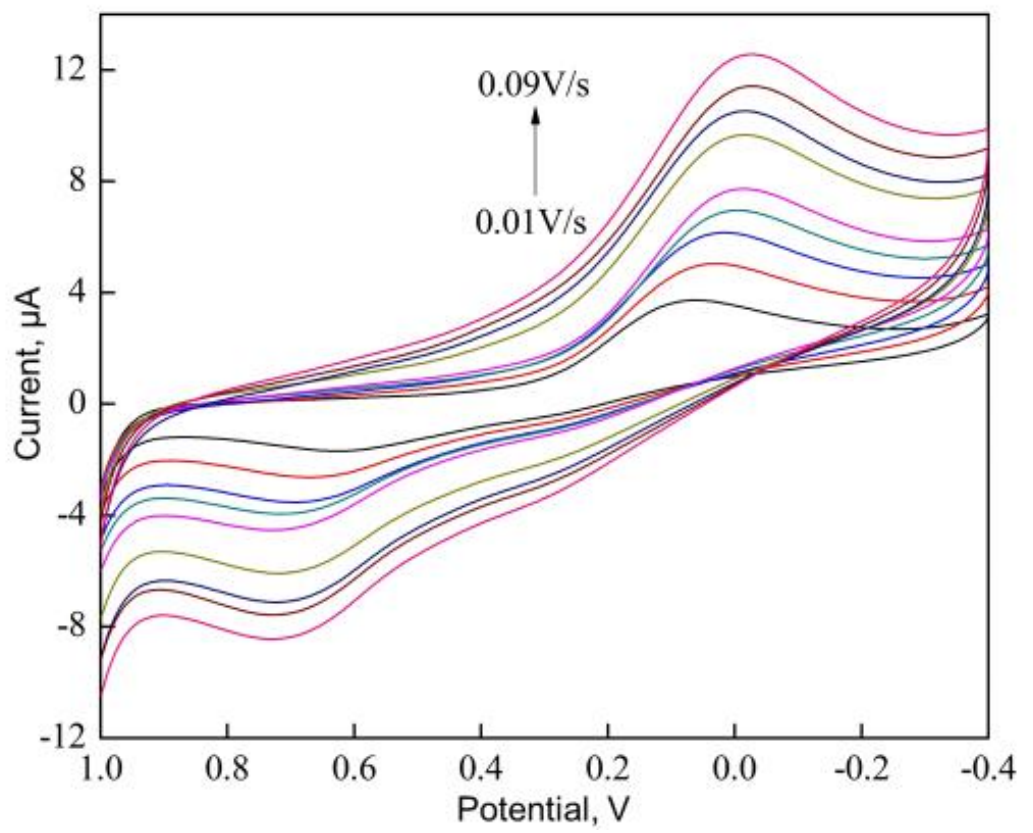

Figure 5. CV curves of GC electrode in diluted Fe $e^{3+}$ solution ( $\mathrm{pH} 3$ ) at different scanning rates (0.01- $\left.0.09 \mathrm{~V} / \mathrm{s}\right)$

Determination of optimal accumulation potential and time

$\mathrm{Fe}^{3+}$ standard solution was taken to investigate the effect of accumulation potential applied prior CV measurements on the peak current (Figure $6 \mathrm{~A}$ ). According to the results, the peak current did not change with the positive shift of the potential when the accumulation potential was changed from $0.8 \mathrm{~V}$ to $-0.2 \mathrm{~V}$, indicating that the reduction degree of iron ions on the electrode surface is practically the same. Hence, $0.4 \mathrm{~V}$ was selected as the optimal accumulation potential. Under this potential, the effect of accumulation time (10-240 s) on the peak current was investigated (Figure 6B). CVs in Figure $6 \mathrm{~B}$ suggest that with the extension of accumulation time, more iron ions are precipitated and enrichment is more complete. At this time, $\mathrm{Fe}^{3+}$ concentration around the electrode increases, and the peak current also increases. $3 \mathrm{~min}$ later, however, the peak current did not change much, demonstrating that adsorption reached saturation. Therefore, $3 \mathrm{~min}$ were selected as the best accumulation time.
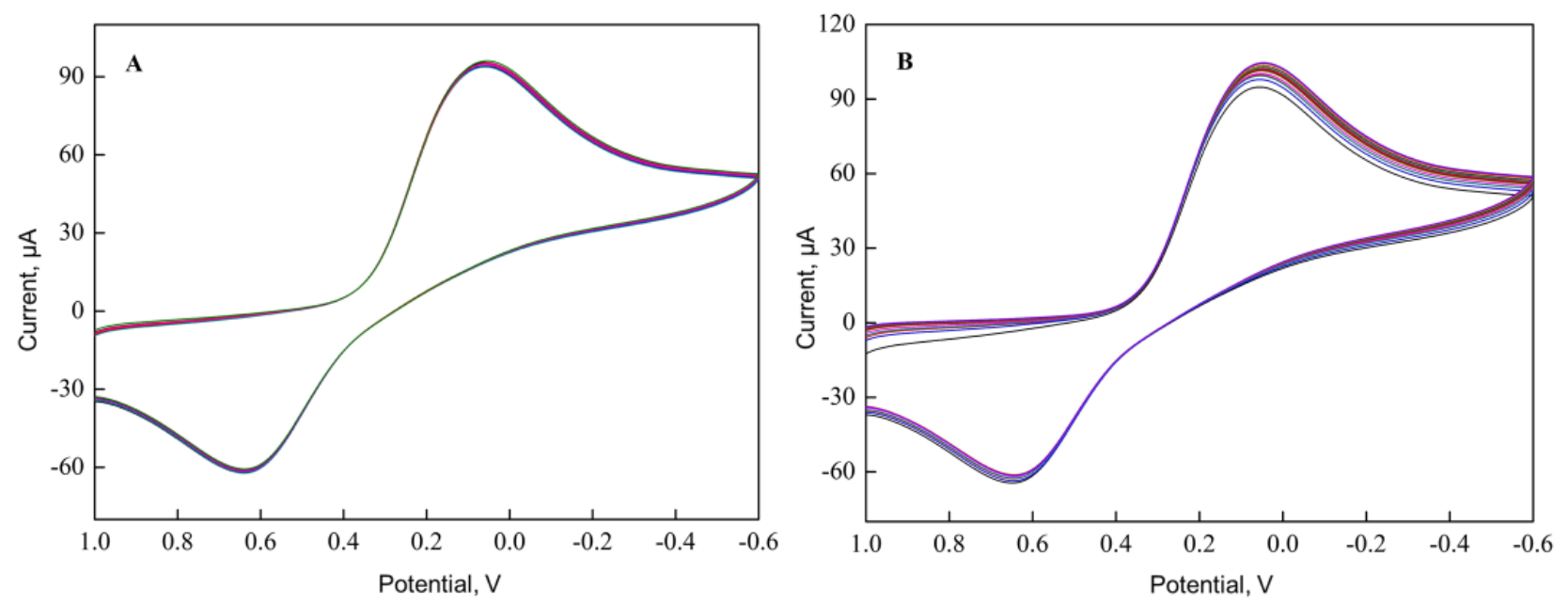

Figure 6. $\mathrm{CV}$ curves of GC electrode in standard $\mathrm{Fe}^{3+}$ solution under $(A)$ different accumulation potentials ( 0.8 to $-0.2 \mathrm{~V}$ ) and (B) different accumulation times (10 to $240 \mathrm{~s}$ ) 


\section{Method validation}

Effect of interfering ions

Since SFGC solution contains $\mathrm{CO}_{3}{ }^{2-}$ ions, $\mathrm{Na}_{2} \mathrm{CO}_{3}$ was added into $0.001 \mathrm{~mol} / \mathrm{L} \mathrm{Fe}^{3+}$ standard solution in order to simulate SFGC solution and to study effect of these ions to determination results [25]. $\mathrm{Na}_{2} \mathrm{CO}_{3}$ concentrations of $0,0.001,0.01$ and $0.1 \mathrm{~mol} / \mathrm{L}$ were added respectively in the standard solution of $\mathrm{Fe}^{3+}$ ions, and measured CVs are shown in Figure 7. No change or different peak is observed in Figure 7. By comparing the peak current values, RSD was found less than $\pm 2 \%$, which suggests that $\mathrm{CO}_{3}{ }^{2-}$ ions do not interfere to the determination of iron ions.

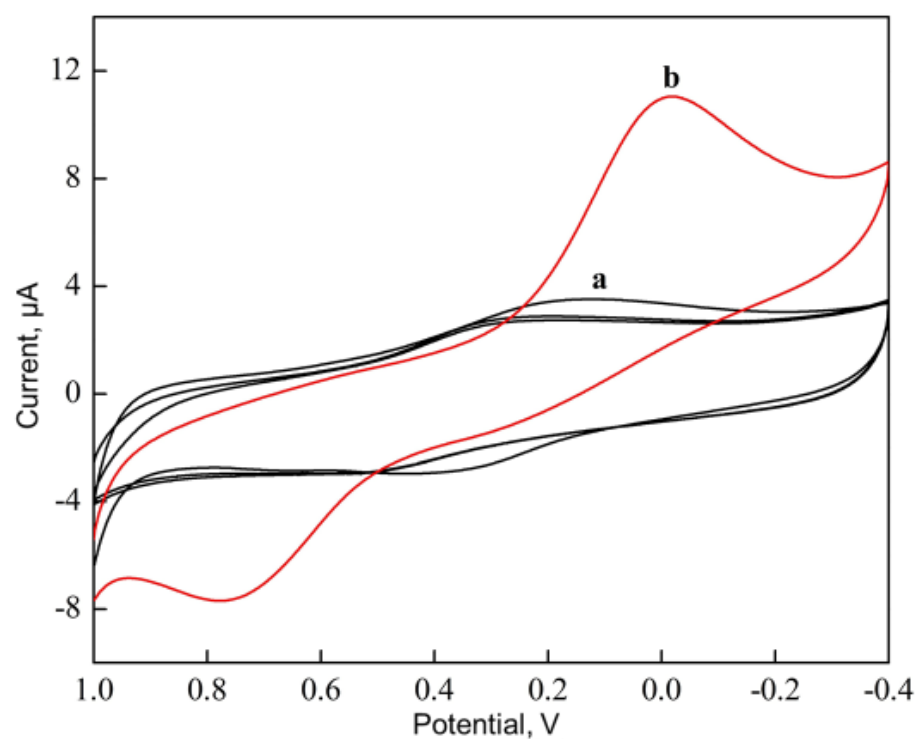

Figure 7. Influence of interfering $\mathrm{CO}_{3}{ }^{2-}$ ions on $\mathrm{CVs}$ of $\mathrm{GC}$ electrode in standard $\mathrm{Fe}^{3+}$ solution for (a) three different concentrations of $\mathrm{Na}_{2} \mathrm{CO}_{3}$, (b) $\mathrm{Fe}^{3+}$ standard solution with three different concentrations of $\mathrm{Na}_{2} \mathrm{CO}_{3}$

\section{Accuracy}

On the basis of the current experiment, $\mathrm{Fe}^{3+}$ standard solutions of 80,100 and $120 \%$ concentrations were respectively added into $1 \mathrm{~g} / \mathrm{L} \mathrm{SFGC}$ solution. After iron content was determined, the measured value was compared with the theoretical value to calculate the recovery rate. The results showed that recovery rates were 100.2, 99.8 and $98.6 \%$, and RSDs were 3.02, 2.06 and $2.36 \%$, respectively. The same method was repeated by adding $\mathrm{Fe}^{2+}$ standard solutions. The results showed that the recovery rates of those three concentrations were 99.1, 99.8 and $100.6 \%$ and RSDs were $1.98,1.56$ and $2.63 \%$, respectively.

Stability and repeatability

In order to investigate stability of the system and repeatability of measured data, six cyclic voltammetry curves in standard $\mathrm{Fe}^{3+}$ and $\mathrm{Fe}^{2+}$ solutions were repeatedly measured according to the experimental conditions determined above [26]. RSD of the peak current was calculated to be $0.9-1.6 \%$, and the peak shape of each curve was good. Therefore, this test method has high reproducibility and high stability, and can be applied in practice.

Limit of detection (LOD) and limit of quantitation (LOQ)

When the concentration of $\mathrm{Fe}^{3+}$ is greater than $5.0 \times 10^{-3} \mathrm{~mol} / \mathrm{L}$ (LOQ), the oxidation peak area does not change with the concentration increase, indicating that $\mathrm{Fe}^{3+}$ ions are adsorbed on the electrode surface. LOD was calculated to be about $1.0 \times 10^{-3} \mathrm{~mol} / \mathrm{L}$ at SNR of 3 times. In the same way, LOD of $\mathrm{Fe}^{2+}$ was determined as $8.9 \times 10^{-3} \mathrm{~mol} / \mathrm{L}$ and LOQ was $2.5 \times 10^{-2} \mathrm{~mol} / \mathrm{L}$. 
Linearity and range

Gradient of standard solution concentrations of $\mathrm{Fe}^{3+}(0.005-0.01 \mathrm{~mol} / \mathrm{L})$ and $\mathrm{Fe}^{2+}(0.025-0.05 \mathrm{~mol} / \mathrm{L})$ were added to $1 \mathrm{~g} / \mathrm{L} \mathrm{SFGC}$ solution, respectively and their CVs are scanned under the optimal experimental conditions (Figures 8 and 9). Linear regression equations for two standard $\mathrm{Fe}^{3+}$ and $\mathrm{Fe}^{2+}$ solutions could be then obtained: $Y=12.85667+2786 \mathrm{X}, \mathrm{R}^{2}=0.9961\left(\mathrm{Fe}^{3+}\right)$ and $\mathrm{Y}=42.32+703.8 \mathrm{X}$, $\mathrm{R}^{2}=0.9924\left(\mathrm{Fe}^{2+}\right)$. The detection limit was low, reaching $\mathrm{mM}$ level. Thereupon, it could be reasoned that iron in the complex would not affect the interference of free iron ions and that the content of free iron ions in any SFGC sample could be calculated according to the standard curve equation.

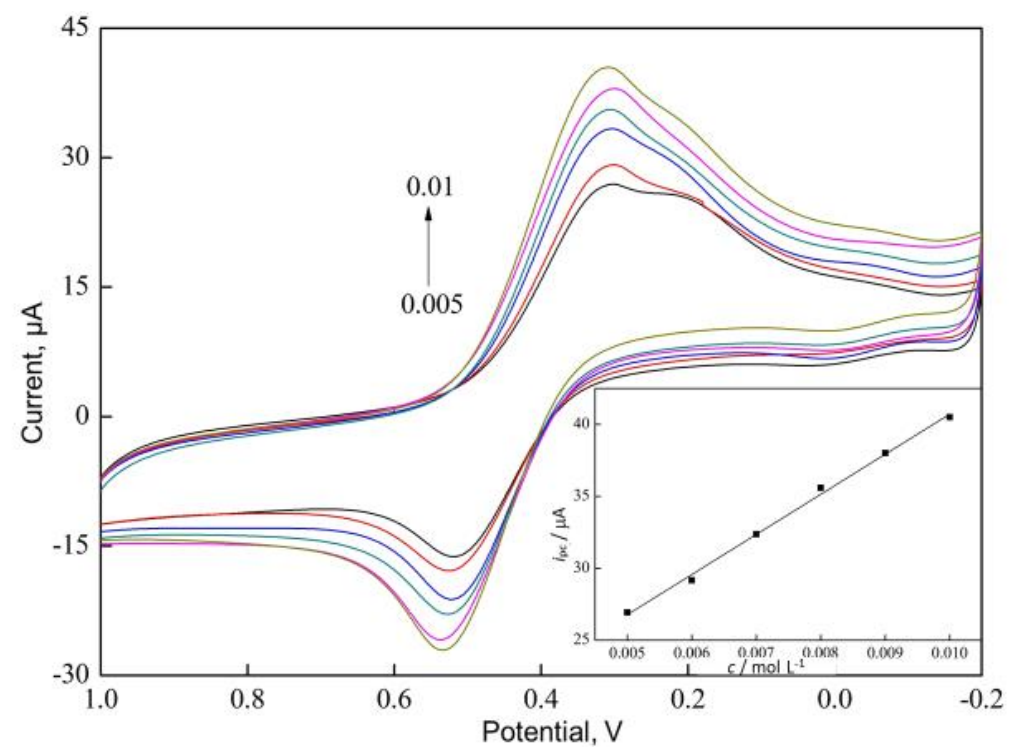

Figure 8. CVs of GC electrode in SFGC solution containing standard Fe $\mathrm{F}^{3+}$ solutions (0.005-0.01 mol/L) and calibration plot (line is linear fit)

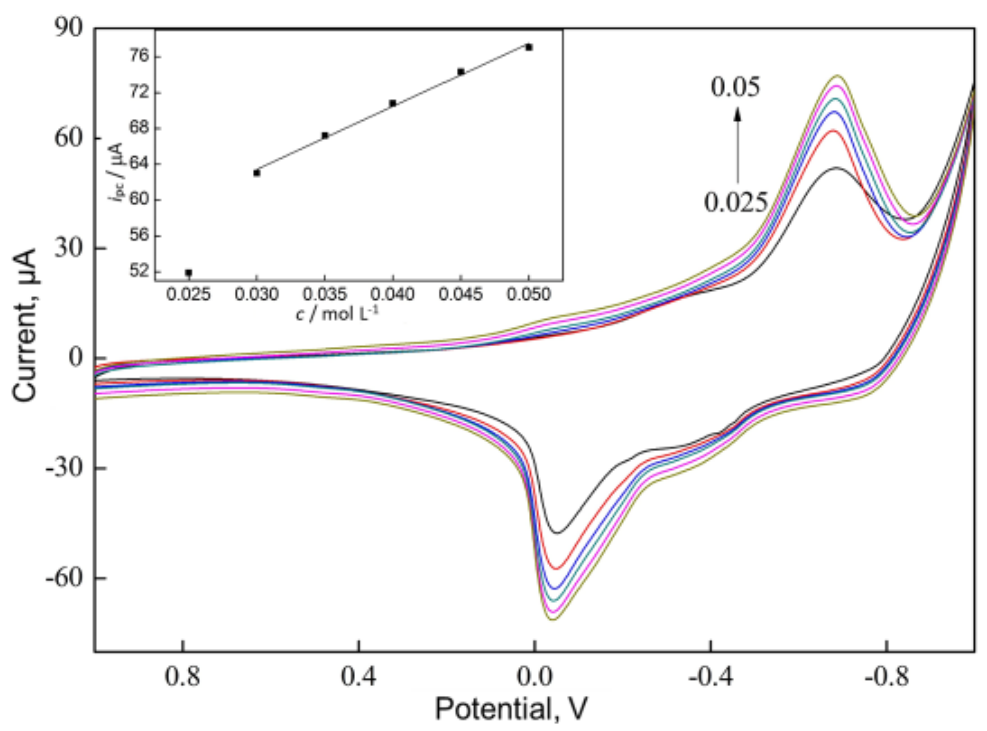

Figure 9. CVs of GC electrode in SFGC solution containing standard $\mathrm{Fe}^{2+}$ solutions $(0.025-0.05 \mathrm{~mol} / \mathrm{L})$ and calibration plot (line is linear fit).

Determination of the total iron content in SFGC

The cyclic voltammetry was employed to scan $1 \mathrm{~g} / \mathrm{L} \mathrm{SFGC}$ solution and $1 \mathrm{~mol} / \mathrm{L} \mathrm{D}$-sodium gluconate solution. In both solutions, however, no characteristic peak of free iron ions is observed (Figure 10a and b). Nevertheless, the characteristic electrochemical behavior can be observed after the acid-hydrolysis of SFGC solution (Figure 10c). These results showed that stability of the 
complexed iron is high because $D$ - sodium gluconate serves as a molecular shell to effectively adsorb the metal iron ions in the solution, forming a stable complex. Therefore, the iron core content is difficult to be determined directly by the electrochemical scanning [27]. When the sample was aciddecomposed, the complexed iron is completely converted into free $\mathrm{Fe}^{3+}$ ions, and the electrochemical redox peak appeared in the potential range of -0.4-1.0 V. The ratio of anode to cathode peak currents (IPC/IPA) is 1.026, what is close to the theoretical value of 1 for the reversible reaction. This means that the redox reaction of iron ions is a reversible process.

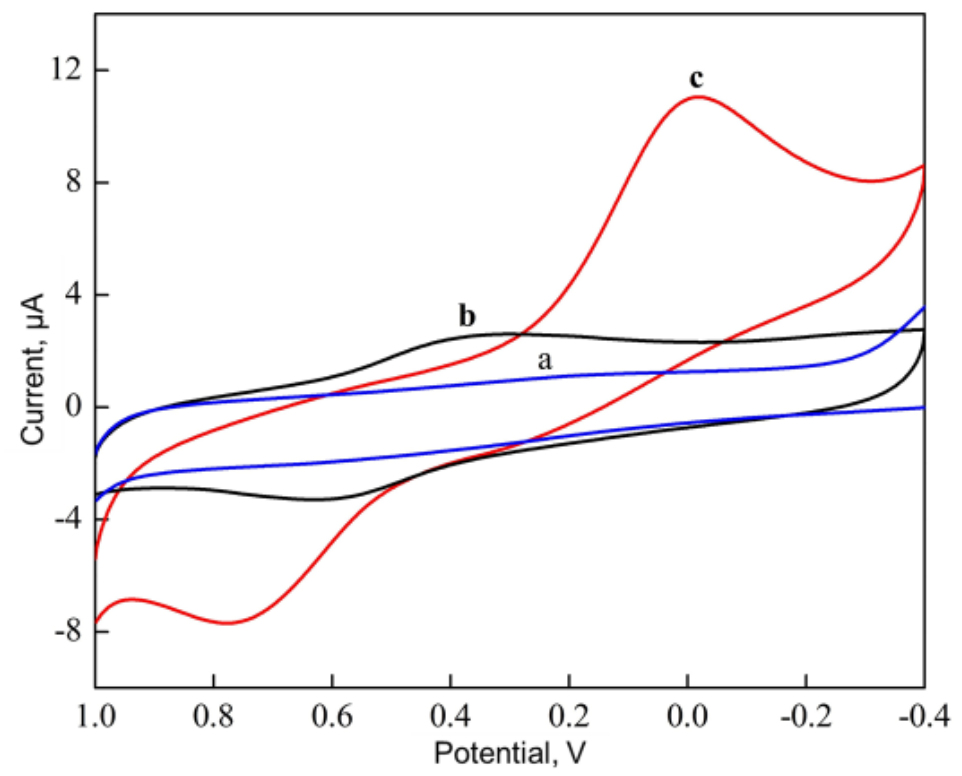

Figure 10. Comparison of cyclic voltammograms of (a) SFGC solution before acid-hydrolysis,

(b) D-SG solution, (c) SFGC solution after acid-hydrolysis

$0.01 \mathrm{M} \mathrm{Fe}^{3+}$ standard solution, $5 \mathrm{~g} / \mathrm{L} \mathrm{SFGC}$ solution and their mixture were acidolyzed at the same time. After the cyclic voltammetry scanning (Figure 11), it can be seen that the characteristic peaks of $\mathrm{Fe}^{3+}$ are similar in shape, but with some horizontal stretching. The results showed that the complex iron can be completely converted to $\mathrm{Fe}^{3+}$ ions by acid-hydrolysis in SFGC solution.

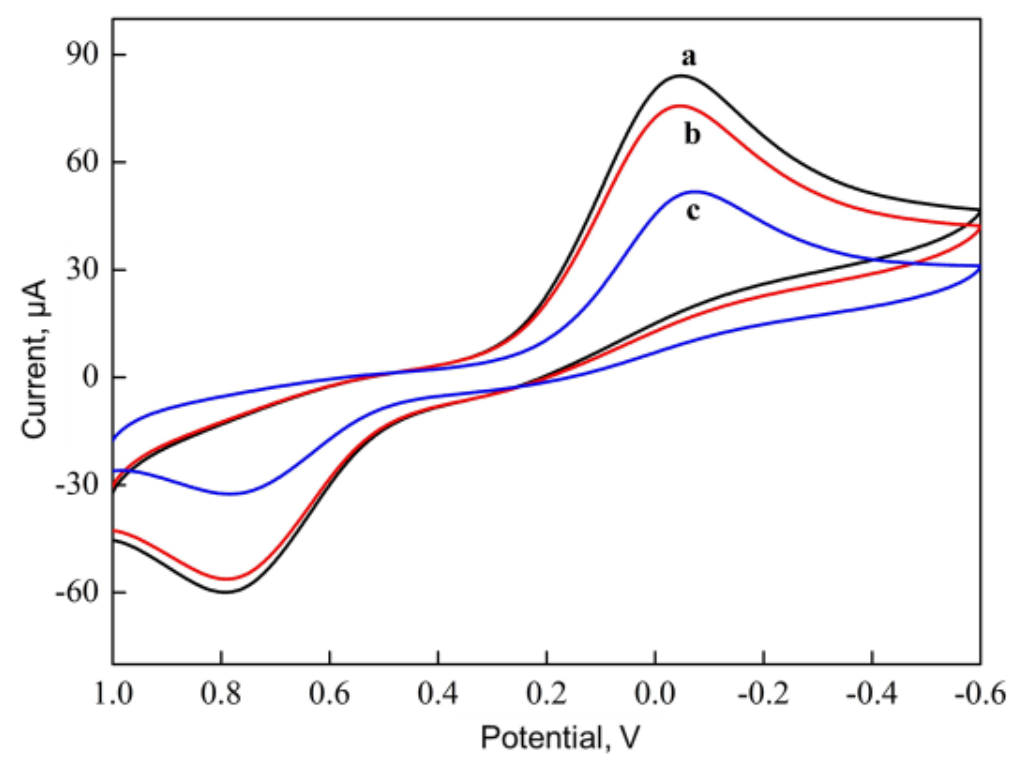

Figure 11. Verification of $\mathrm{Fe}^{3+}$ characteristic peaks in solutions of (a) $\mathrm{FeCl}_{3}$,

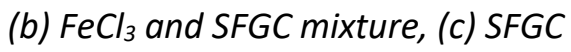


Optimization of acid hydrolysis conditions

The electrochemical scanning results of reduction peak currents $\left(i_{\mathrm{pc}}\right)$ in SFGC solutions after acidhydrolysis at different concentrations of hydrochloric acid solution and different temperatures are compared in Table 1. It is shown that iron core in the complexing iron could be completely released and converted into free $\mathrm{Fe}^{3+}$ ions by acid-hydrolysis with $5 \mathrm{~mol} / \mathrm{mL}$ hydrochloric acid solution for 5 min. The temperature has small effect on the acid-hydrolysis process, which can be carried out directly at room temperature.

Table 1. Determination of acid-hydrolysis conditions

\begin{tabular}{lccccccc}
\hline & \multicolumn{3}{c}{$\mathrm{HCl}$ concentration, moll/L } & \multicolumn{3}{c}{ Temperature, ${ }^{\circ} \mathrm{C}$} \\
\cline { 2 - 8 } & 1 & 3 & 5 & 7 & $\mathrm{RT}$ & 4 & 20 \\
\hline Acid-hydrolysis $5 \mathrm{~min}-i_{\mathrm{pc}}{ }^{\mathrm{a}} / \mu \mathrm{A}$ & 9.85 & 10.79 & 11.04 & 11.12 & 11.04 & 10.99 & 11.08 \\
Acid-hydrolysis 10 min $-i_{\mathrm{pc}}{ }^{\mathrm{a}} / \mu \mathrm{A}$ & 9.85 & 10.82 & 11.11 & 11.09 & 11.09 & 11.03 & 11.07 \\
\hline $\mathrm{a}_{\mathrm{ipc}}$ : Reduction peak current & & & & & & &
\end{tabular}

Linearity range

Standard solutions of $\mathrm{Fe}^{3+}$ ions after acid-hydrolysis at different concentrations were scanned under optimal conditions (Figure 12A). Within the range of $0.01-0.04 \mathrm{~mol} / \mathrm{L}$, the peak currents presented a good linear relationship with $\mathrm{Fe}^{3+}$ concentration $(\mathrm{Y}=2.27714+836 \mathrm{X}), \mathrm{R}^{2}=0.9957$ (Figure 12B). Therefore, the total iron content in any SFGC sample solution can be obtained using this linear fitted equation.
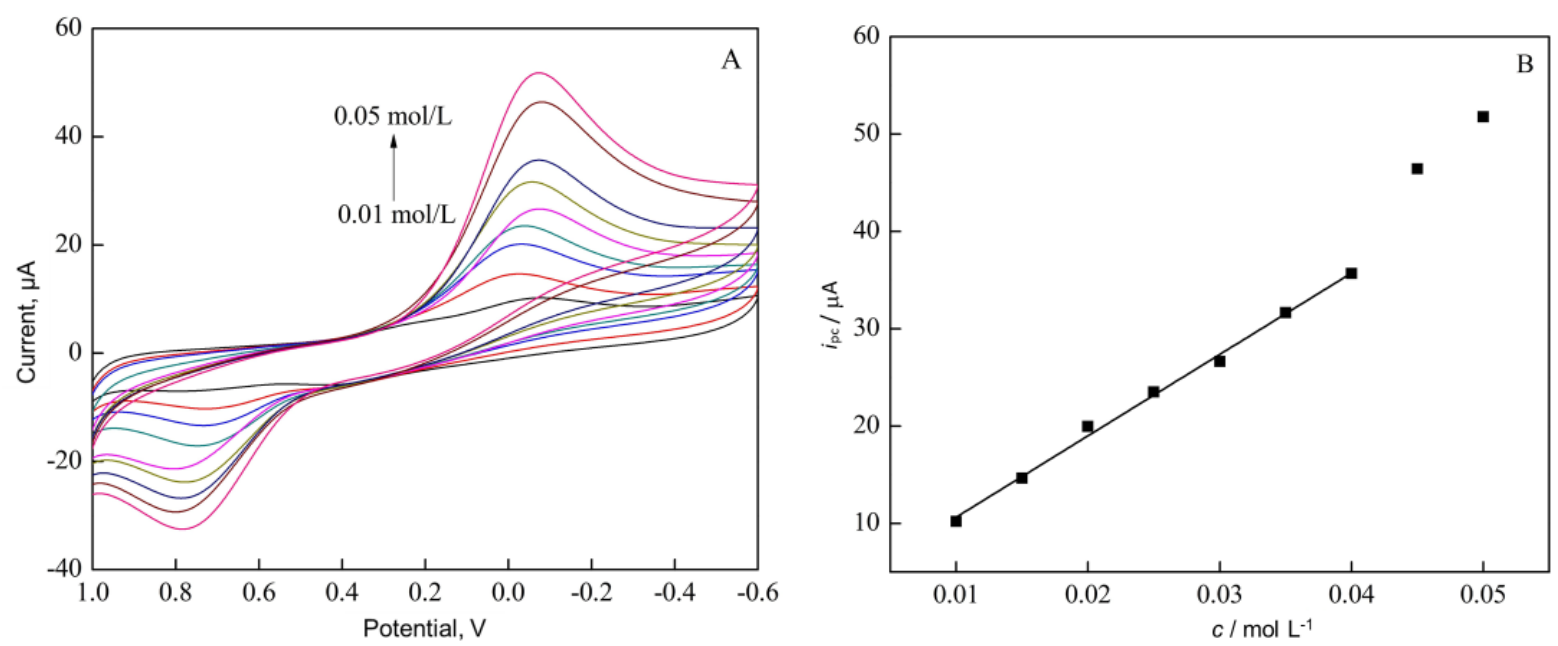

Figure 12. (A) CV curves for different concentrations of standard Fe ${ }^{3+}$ solution after acid-hydrolysis of SFGC, (B) reduction peak current vs. concentration of $\mathrm{Fe}^{3+}$

\section{Application}

Three sample solutions with concentration of $0.1 \mathrm{~g} / \mathrm{L}$ were prepared by SFGC containing $10 \mathrm{mg}$ iron, and the content of free iron in the samples was determined by cyclic voltammetry under the optimal conditions. Further, acid-hydrolysis was carried out before the sample was measured. The total iron content in SFGC was calculated by the linear regression equation, and RSD value was then acquired (Table 2).

Table 2. Determination of free iron ions and total iron content in SFGC.

\begin{tabular}{ccccc}
\hline \multirow{2}{*}{ Sample number } & \multirow{2}{*}{ Free iron } & \multicolumn{3}{c}{ Total amount of iron } \\
\cline { 3 - 5 } & & Found $^{\mathrm{a}}, \mathrm{mg}$ & Relative to labeled, $\%$ & RSD, $\%$ \\
\hline 1 & $--{ }^{-}$ & 9.89 & 98.9 & 0.75 \\
3 & -- & 10.16 & 101.6 & 1.65 \\
& -- & 10.08 & 100.8 & 1.07 \\
\hline
\end{tabular}

${ }^{a}$ mean value of 6 parallel measurements; ${ }^{b}$ no free iron ions were detected 


\section{Conclusions}

In this paper, the contents of free iron ions and total iron in the system were detected by the cyclic voltammetry scanning with glassy carbon electrode. The optimized experimental conditions were defined as solution $\mathrm{pH} 3$, potential scanning rate $0.05 \mathrm{~V} / \mathrm{s}$. Before $\mathrm{CV}$ measurements, enrichment potential $0.4 \mathrm{~V}$ and enrichment time 3 min were found optimal. Free $\mathrm{Fe}^{3+}$ ions were measured in the range of $0.005-0.01 \mathrm{~mol} / \mathrm{L}$, while free $\mathrm{Fe}^{2+}$ ions were measured in the range of 0.025-0.05 mol/L. The peak current was linearly correlated with the concentration of iron ions, and the results showed that the method is stable and reproducible. The chelated iron can be completely converted to $\mathrm{Fe}^{3+}$ ions by acid-hydrolysis under $5 \mathrm{~mol} / \mathrm{L}$ hydrochloric acid solution for $5 \mathrm{~min}$, and then calculated according to the linear relationship.

Compared with the previous methods for determination of iron content, here proposed electrochemical detection method can determine the contents of free iron ions and total iron in the system. Also, the proposed method has the advantages of simple operation, short response time, good sensitivity, and accurate stable results. This method can also be used for determination of other complexes of iron.

Acknowledgements: The investigations were carried out with the equipment of Administrative Office of Laboratory and Equipment, Southwest University.

\section{References}

[1] X. L. Zhan, F. S. Wang, J. R. Wang, J. Wang, Medical Journal of Qilu 5 (2008) 467-468.

[2] T. S. Koskenkorva-Frank, G. Weiss, W. H. Koppenol, S. Burckhardt, Free Radical Biology and Medicine 65 (2013) 1174-1194.

[3] Z. Yang, H. J. Luo, Foreign Medical Sciences (Section of Hygiene) 2 (2006) 90-93.

[4] M. Kowalczyk, M. Banach, J. Rysz, Journal of Nephrology 24 (2011) 717-722.

[5] C. N. Tang, Anhui Chemical Industry 38 (2016) 1-3.

[6] T. Mitsuoka, Bioscience of Microbiota, Food and Health 33 (2014) 117-128.

[7] K. Mao, Y. X. Ma, H. C. Pan, H. Liu, Chinese Journal of New Drugs 24 (2015) 659-663.

[8] Y. X. Ma, K. Mao, T. Mo, H. C. Pan, H. Liu, Food Science 37 (2016) 64-70.

[9] Y. X. Ma, W. T. Wang, J. J. Wu, H. C. Pan, H. Liu, Food Science 37 (2016) 46-51.

[10] Y. X. Ma, M. Wang, D. Li, H. C. Pan, H. Liu, Food Science and Technology Research, 22(5) (2016) 639-646.

[11] Y. Li, C. X. Wang, Y. Shang, S. Z. Shang, J. W. Guo, Metallurgical Analysis 31 (2011) 72-75.

[12] S. Khan, R. Dashora, A. K. Goswami, D. N. Purohit, Reviews in Analytical Chemistry 23 (2004) 1-74.

[13] H. J. Hu, Y. Tang, H. S. Ying, M. H. Wang, P. Y. Wan, X. J. Yang, Talanta 125 (2014) $425-431$.

[14] C. D. Stalikas, A. Ch. Pappas, M. I. Karayannis, P. G. Veltsistas, Microchimica Acta 142 (2003) 43-48.

[15] J. Bok-Badura, A. Jakobik-Kolon, M. Turek, S. Boncel, K. Karon, RSC Advances 5 (2015) 101634-101640.

[16] A. M. Pisoschi, C. Cimpeanu, G. Predoi, Open Chemistry 13 (2015) 824-856.

[17] M. M. Ghoneim, H. S. El-Desoky, M. M. Abdel-Galeil, Bioelectrochemistry 81 (2011) 65-73.

[18] K. S. Ahn, B. K. Kim, W. Y. Lee, Electrochemistry Communications 58 (2015) 69-72.

[19] J. J. Wu, W. T. Wang, M. Wang, H. Liu, HC. Pan, International Journal of Electrochemical Science 11 (2016) 5165-5179.

[20] D. D. Kong, W. J. Kong, Z. H. Khan, P. Y. Wan, Y. M. Chen, M. H. Yang, Fuel 182 (2016) 266-271.

[21] B. G. Shilpashree, S. Arora, V. Sharma, A. K. Singh, Innovative Food Science \& Emerging Technologies 32 (2015) 165-171.

[22] P. C. Pandey, D. Panday, Journal of Electroanalytical Chemistry 763 (2016) 63-70.

[23] E. S. Oliveira, D. R. Gramacho, C. D. Silva, F. Silveira, J. Z. Santos, Z.N. Rocha, Journal of Molecular Catalysis A: Chemical 422 (2016) 198-206.

[24] Z. S. Zhang, X. M. Wang, Z. P. Han, L. Yin, M. X. Zhao, S. C. Yu, Bioorganic \& Medicinal Chemistry Letters 22 (2012) 489-492.

[25] A. M. Beltagi, O. M. Abdallah, M. M. Ghoneim, Talanta 74 (2008) 851-859. 
[26] Z. K. Xie, L. H. Wei, Q. Yang, M. Yang, H. C Pan, H. Liu, Iranian Journal of Pharmaceutical Research 15 (2016) 119-130.

[27] D. Merli, A. Profumo, C. Dossi, Journal of Pharmaceutical Analysis 2 (2012) 450-453.

(C2020 by the authors; licensee IAPC, Zagreb, Croatia. This article is an open-access article distributed under the terms and conditions of the Creative Commons Attribution license (http://creativecommons. org/licenses/by/4.0/) 